\title{
Effect of Plant Growth Promoting Rhizobacteria on Soil Profile, Growth Physiology and Antioxidant Activity of Stevia rebaudiana Bertoni
}

\author{
Shashi Kant Shukla ${ }^{1 *}$, S Krithika ${ }^{2}$, Shraddha Shukla ${ }^{3}$ and Anupam \\ Dikshit $^{4}$ \\ ${ }^{1}$ Anupam Rural Laboratory, Centre of Science and Society, IIDS, University of \\ Allahabad, Allahabad, India \\ ${ }^{2}$ Brandenburg University of Technology (BTU) Cottbus-Senftenberg, Germany \\ ${ }^{3}$ Nanotechnology Application Centre, University of Allahabad, Allahabad, India \\ ${ }^{4}$ Biological Product laboratory, Botany Department, University of Allahabad, \\ Allahabad, India \\ *Corresponding Author: Shashi Kant Shukla, Anupam Rural Laboratory, Centre of \\ Science and Society, IIDS, University of Allahabad, Allahabad, India.
}

Received: April 15, 2020

Published: June 08, 2020

(C) All rights are reserved by Shashi Kant

Shukla., et al.

\section{Abstract}

The present study was performed with the main objective of investigation of enhancement in the growth and antioxidant activity of Stevia rebaudiana, Bertoni, a medicinal plant and chief source of stevioside, natural sweetener. The whole experiment was followed by macro and micronutrients analysis of used soil for pot experiment. In the analysed concentration ratio; potassium was greater than and phosphorous. So, there was a need to dissolve these nutrients into the usable form; Paenibacillus polymyxa was selected due to having these characteristics. The results, observed in 0,10 and 20 days, showed that in comparison to control, inoculation with experimented soil bacterium, considerably increased root and shoot length as well as no and size of leaves in plant. The positive impact of the performed experiments was obtained after 10 and 20 days respectively. Furthermore, antioxidant efficacy of $S$. rebaudiana was done using DPPH method which confirms the plant to be free radical scavenger. The conclusion of the experiment showed the efficacy of P. polymyxa on escalation of Stevia.

Keywords: Stevia; Stevioside; Macro and Micronutrients; Antioxidants; Free Radicals

\section{Introduction}

Stevia rebaudiana Bertoni is being used as a medicinal herb in many countries which is native of certain section of South America [1]. Its leaves contain sweet rich steviol glycosides and other medicinal properties [2]. The world authorities have permitted to use natural sweetener obtained from Stevia and as a part of food also. Stevioside is a major content of leaves which is a type of steviol glycosides, 300 times sweeter than sugar [1]. Thus, it is need of present scenario to cultivate $S$. rebaudiana. Its cultivation can be achieved easily in red and sandy soil with pH 6.5 to 7.5. In our country it is grown in few portion of Rajasthan, Maharashtra, Kerala and Odissa [3]. But due to restricted time being of seed feasibility and very low germination rate its farming is not simple [1].
This difficulty can be easily solved by use of a group of eco-friendly, soil microbes commonly known as plant growth promoting bacteria [4]. These bacteria are found in the rhizospheric zone of soil and increase the quality and quantity of crop as their requirements [5-7]. Some important PGPRs are Pseudomonas fluorescens, Bacillus subtilis, Pseudomonas putida, Paenibacillus elgii and Paenibacillus polymyxa etc [8]. These reported bio-inoculants diversely improve the crop yield $[9,10]$ through mechanisms such as establishment of endophytic populations [11,12] on interactions to root interior for the benefits and better adaptations with the host plants.

Another factor for plant growth promotion is the quality and type of soil present. The unsymmetrical proximity of nutrients can play vital role in production of crop also. For Stevia cultivation, 
good drainage soil is required whereas long moisture retaining soil should be avoided. Black soil, amongst all soils is found to be the most suitable for aforesaid plant with $6-7 \mathrm{pH}$.

Potassium, Phosphorous, Calcium, Zinc, Sulphur and Iron are some significant macro and micronutrients of soil. These nutrients increase the crop yield when available in balanced ratio and decreases the same when found in unbalanced way. PGPB makes solubilises the inorganic forms of $\mathrm{P}$ and $\mathrm{K}$ into organic ones. Generally, plant growth promoting bacteria solubilises easily to $\mathrm{P}$ in comparison to $\mathrm{K}$ but in case of $P$. polymyxa performs efficiently the same mechanism for both.

It is well known that Stevia is a medicinally important herb and have the potential to become chief source of natural sweetener in food industry. The scientists of globe are trying to cultivate the Stevia as normal crops. Hence, an effort was made in the present study to observe the impact of a soil microbe for easy cultivation of $S$. rebaudiana in lights of soil and nutrients analysis.

\section{Materials and Methods}

All the experiments and soil collection was done in Biological Product Laboratory, Botany Department, University of Allahabad.

\section{Soil analysis}

The collected soil was cleaned, sieved followed by air dried, overnight desiccation and autoclaved at standard temperature and pressure. The nutrient analysis was done at Indian Farmer Fertilizer cooperative ltd., (IFFCO) Phulpur, Prayagraj.

\section{Procurement of PGPR strain and plant}

Paenibacillus polymyxa (MTCC-9489) was obtained from Microbial type culture collection, Chandigarh, India and the plant Stevia rebaudiana Bertoni seed beds from Bioved Research Institute of Agriculture and Technology Allahabad, Prayagraj.

\section{Phosphate solubilisation activity}

Phosphate is one of the most important macronutrient for the growth of plants. Most of the essential plant nutrients especially $\mathrm{P}$, remain in its insoluble form in the soil. So, the phosphate solubilising bacterium will be more suitable for growth of plants. P solubilising activity was observed in Pikovskaya plates suggested by Sundara-Rao., et al. in 1963 [13].

\section{Potassium solubilising activity}

Potassium (K) is a vital plant nutrient and is absorbed copiously in the form of cation which plays a significant role in the growth, metabolism and improvement of plants. This activity was observed in modified Aleksandrov medium plates by the spot test method suggested by Sindhu., et al. in 1999 [14].

\section{Indole acetic acid (IAA) production}

Production of Auxin was observed by inoculating bacterial culture in Peptone broth with 1\% tryptophan for $48 \mathrm{hrs}$ at body temperature. Then after by mixing $1 \mathrm{ml}$ of Kovac's reagent in the existing culture tube and shake for 15 minutes. The emergence of red or dark pink colour at the top is the authentication of IAA.

\section{Catalase test}

The 24 hrs old culture of Paenibacillus polymyxa on Luria bertani medium, put as a drop on a glass slide which was followed by the addition of 3 - 5 drop of $0.3 \%$ of Hydrogen Peroxide. The appearance of air bubbles was considered as a Catalase positive result.

\section{Inoculum preparation}

In this pot experiment, $\mathrm{P}$ and $\mathrm{K}$ solubilizer Paenibacillus polymyxa strain MTCC- 9489 was used as biofertilizer. Experimented strain was cultured in Muller Hinton Broth medium and they were kept for $24 \mathrm{~h}$ in a shaking incubator at $28^{\circ} \mathrm{C}$ and $150 \mathrm{rpm}$. For the treatments, inoculum was prepared according to the 0.5 McFarland standards containing $1-2 \times 10^{8} \mathrm{cell} / \mathrm{ml}$ at $625 \mathrm{~nm}$ absorbance [15].

\section{Selection of plant}

Classification/taxonomical position

Kingdom: Plantae

Class: Dicotyledons

Sub class: Polypetalae

Series: Thalamiflorae

Order: Asterales

Family: Asteraceae

Genus: Stevia

Species: rebaudiana 


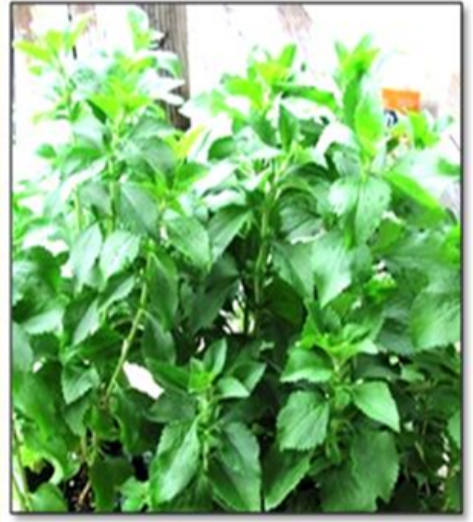

Figure

The vegetative part was used for the whole study. The seed beds of Stevia plants were procured from Bioved Research Institute of Agriculture and Technology Allahabad, Allahabad. These seed beds were first sprayed with water in order to avoid dryness.

\section{Experimental design}

The 10 days old vegetative plants were selected for the present study. The plants were grown in pods, filled with autoclaved soil which was further analysed in IFFCO laboratory, Phulpur for micro and macronutrient measurement. The experiments were basically designed in such a way to visualise and compare the effects of $P$. polymyxa in the stimulation of each part of the plant such as root, shoot, leaves etc. In the same order, cultivated plants were treated with P. polymyxa in the form of bio-inoculants which was prepared in Muller Hinton Broth medium (MHB) according to the 0.5 McFarland turbidity. Further, autoclaved soil was filled in 16 pods with at least 3 - 4 plantlets in each and roots were completely covered with soil. These 16 pods where divided for the treatment with $P$. polymyxa and control respectively. The amount of PGPR used for the treatment was $20 \mathrm{ml}$ each and distilled water for control treatment. Observation of these plants along with the measurement and effect of their treatment on the basis of root length, shoot length, number of leaves and number of branches etc. was carried out after periods of 0 days, 7 days and 14 days respectively. The whole experiment was repeated twice with three replicates including the control.

\section{Antioxidant activity}

The measurement of total antioxidant activity of methanol extract was assayed using DPPH (2, 2' diphenyl-1-picrylhydrazyl) radical as substrate, following the method described by Blois [16] with minor modifications. In this assay, $0.05 \mathrm{ml}$ of extract solution was added to $1.9 \mathrm{ml}$ of $60 \mu \mathrm{M}$ methanolic DPPH solution and absorbance was read at $517 \mathrm{~nm}$. The radical scavenging activity was calculated using equation $(\mathrm{AC}-\mathrm{AS}) / \mathrm{AC} \times 100 ; \mathrm{AC}=$ absorbance of control, AS = absorbance of sample solution.

\section{Results and Discussion}

Soil analysis: Major findings

The results of presence of macronutrient elements in both autoclaved and non-autoclaved soil samples along with their fertilizer recommendations were suggested by IFFCO, Phulpur, Prayagraj. According to the laboratory reports the available potassium (K) in used soil was $269 \mathrm{~kg} /$ hectare, greater than its original recommendations whereas another important macronutrient i.e. phosphorous (P) was $15 \mathrm{~kg} /$ hectare which is just half of its recommendations. The uneven availability of the nutrients might be due to the presence of unsolvable and non-usable form of potassium as well as phosphorous. Further, micronutrients analysis reflects that copper (1.74 ppm), manganese (4.32 ppm) and zinc (1.34 ppm) were found in higher concentration than iron (6.80 ppm) and sulphur (13.00 ppm). The choice of $P$. polymyxa for investigation was also due to its phosphate solubilising and potash solubilising properties [15]. The aforesaid bacterium was also found very good source for Catalase activity and IAA production.

\section{Catalase test}

P. polymyxa was found Catalase positive (Table 1). It is usually observed that the bacterial strains in which the Catalase activity is prevalent are highly resistant to environmental, mechanical and chemical stress. Some other workers have reported similar findings of multiple plant growth promoting activities among PGPR.

\section{Indole acetic acid production}

The P. polymyxa was found very good source of IAA production (Table 1). The abundance of precursors and uptake of bacterial IAA by plant are the two main factors that affect the ability of PGPB to produce IAA in the rhizosphere. Hormones and other microbial mechanism are one of the important factors of plant growth.

\section{Phosphate solubilisation}

Phosphorous (P) is one of the most vital macronutrient present in the soil which is essential for the improved growth and devel- 


\begin{tabular}{|l|c|c|}
\hline S. No. & Characteristics/Tests & Results \\
\hline 1. & Grams stain & Gram-positive \\
\hline 2. & Shape & Ellipsoidal and rod \\
\hline 3. & Catalase activity & + \\
\hline 4. & IAA Production & + \\
\hline 5. & Phosphate Solubilizing test & + \\
\hline 6. & Potassium Solubilization test & + \\
\hline
\end{tabular}

Table 1: Morphological and biochemical characteristic of P. polymyxa.

opment of flora [17]. Its least availability also makes it significant when compared to nitrogen, most abundant in environment. $P$. polymyxa was found to be a very good phosphate solubilizer (Table 1 ) as reflected by clearing zone as shown in the figure $1 \mathrm{~A}-1 \mathrm{~B}$. The zone of clearance is considered as a result of release of some low molecular weight organic acids by the experimented strain. These organic acids convert the inorganic phosphate into soluble forms that can be easily used by plants.
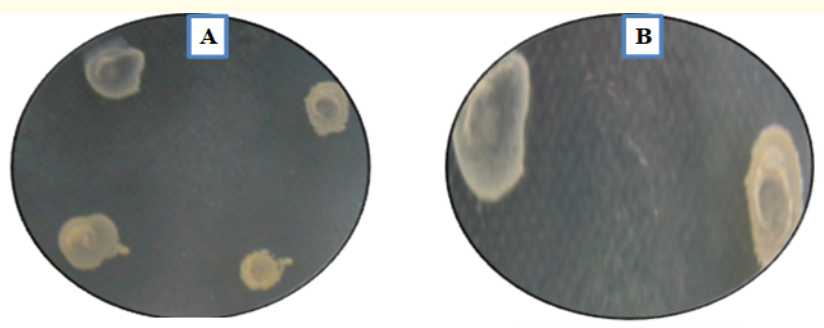

Figure 1: The phosphate solubilization activity of Paenibacillus polymyxa on Pikovskaya agar plates (A-B).

\section{Potassium solubilizing activity}

Potassium (K) is third abundantly available macronutrient in the environment, engrossed in the form of cation, playing a crucial role in growth and development of plants. Most of the potassium on earth exists in the form of silicate minerals and insoluble rocks [18]. P. polymyxa was found as a good source of phosphate solubilizer.

\section{Effect of $P$. polymyxa on Stevia rebaudiana}

On the treatment of $P$. polymyxa, plant showed a significant growth and development in the whole part such as shoot length, root length, total length, number and size of leaves (Figure 2) as compared to the control plant. Histogram clearly reflects the positive effect of $P$. polymyxa on aforementioned growth parameters of experimented plant. The measurement of shoot and root lengths, number and size of leaves was done on the same (0) day, $10^{\text {th }}$ and $20^{\text {th }}$ days respectively. Same day readings showed no effect because the treatment was given on that day but, the second readings i.e. After 10 days of treatment there was significant increase in all parameters such as shoot length and root length as compared to control. It was also remarkable that the development in root and stem length is due to the production of Auxins [19] as well as more nutrients are absorbed from rhizosphere of roots induced by P. polymyxa which is a good phosphorous and potash solubilizer. This enhanced growth in stem length and increased leaves no led to the highest photosynthesis resulting in formation of enough food which is necessary for plant growth [20].

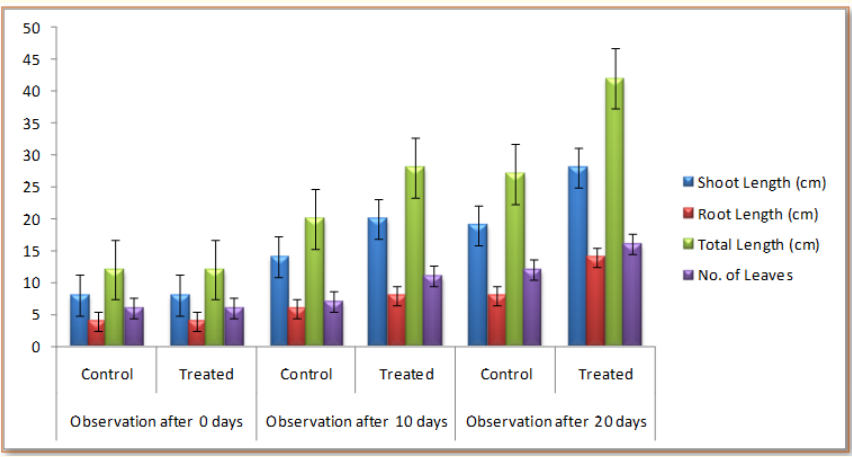

Figure 2: Effect of Paenibacillus polymyxa on the shoot length, root length, total length and number of leaves of Stevia rebaudiana. Bar represents the standard error.

The third observation was made after 20 days of treatment and was found to have extremely good results. Shoot length was $9 \mathrm{~cm}$ more than control plant and $8 \mathrm{~cm}$ greater than the previous one i.e. after 10 days. In the same way root length was also increased in an impressive way along with the increased no and size of leaves from their own control as well as from former ones when compared.Our findings also reveal that use of $P$. polymyxa can boost the farming of $S$. rebaudiana, leading to the production of stevioside. The application of aforementioned PGPR strain seems to be ultimately effective in improving growth of the plant, as a result of excellent plant nutrient uptake. In addition to the higher concentration of potash and others which are solubilized by the experimented strain into the usable form, would also be a reason for such an excellent growth. 
It is also known that P availability in soils is important for the uptake of soil nitrogen and its utilization in plants. Therefore, more available P due to its solubilization by inoculated PSB could lead to improved $\mathrm{N}$ uptake or nitrogen fixation by $P$. polymyxa. These aspects have caused increased shoot, root, total length, no and size of leaves of $S$. rebaudiana. Several attempts were made artificially for the production of stevioside, a major constituent of $S$. rebaudiana responsible of sweetness. Thus, the use of $P$. polymyxa was precisely aimed for increasing the production of $S$. rebaudiana to fulfill the demand of stevioside and to reduce the cost. In addition, the use of $P$. polymyxa as biofertilizer has also shown the efficient path for the substitution of synthetic fertilizers. In the same way, it can solve the most important global problem of environmental pollution and creates a boom in the agriculture industry.

Antioxidant efficacy of $S$. rebaudiana against DPPH free radicals:

DPPH method is used extensively for screening of antioxidants and for determining relative antioxidant efficacy [21] which is also considered as role model for lipid loving radicals. The reducing efficacy of DPPH was determined by declining its absorbance at $517 \mathrm{~nm}$, which is induced by antioxidants. The present results suggest that the experimented plant was found to be a free radical scavenger. On the DPPH free radical, aqueous leaf extract had good amount of radical scavenging effect with its significant concentrate compared to that of ascorbic acid, whose scavenging effect of leaf extract was exciting. The antioxidant activity of $1250 \mu \mathrm{g} / \mathrm{ml}$ control Stevia plant leaves corresponds to $57.57 \mu \mathrm{g} / \mathrm{ml}$ ascorbic acid whereas, the same amount of Stevia leaves treated with P. polymyxa was equal to $83.13 \mu \mathrm{g} / \mathrm{ml}$ of ascorbic acid.

\section{Conclusion}

A majority of people are facing the problem of diabetes which has been a big issue in present scenario, ultimately drawing the attention towards its management. Few medicinal plants provide better cure as they are cheap, nontoxic, trustworthy and competent when compared to others and $S$. rebaudiana is one of them which exhibited very good antioxidant activity too. The growth of $S$. rebaudiana after treatment with $P$. polymyxa was enhanced thereby meeting the demand of the plant in the society.

\section{Acknowledgements}

Thanks are due to Coordinator, Centre of Science and Society; Head, Department of Botany, University of Allahabad, India for providing lab facilities and UGC for financial support.

\section{Bibliography}

1. Shukla SK., et al. "Bio-Sweetener (Stevia rebaudiana Bertoni): Boon for rural India". Organic and Medicinal Chemistry International Journal (2017): 03.

2. Salerno G and Curatti L. "Origin of sucrose metabolism in higher plants: when, how and why?" Trends in Plant Science 8 (2003): 63-69.

3. Goyal SK., et al. "Stevia (Stevia rebaudiana) a bio-sweetener: a review". International Journal of Food Sciences and Nutrition 61.1 (2010): 1-10.

4. Shukla SK., et al. "Prediction and validation of Gold nanoparticles on plant growth promoting rhizobacteria (PGPRs): a step towards development of nano-biofertilizers". Nanotechnology Reviews (2015).

5. Shukla SK., et al. "Impact of eco-friendly soil microbe on Macrotyloma uniflorum (lam.) Verdc: a medicinal pulse". International Journal of Life science and Pharma Reviews 7 (2017): 2.

6. Shukla SK., et al. "Impact of Pseudomonas putida on the growth parameters of Fenugreek (Trigonella foenum graecum L.): a traditional herbal boon for rural population". Science and Technology 5 (2017): 2.

7. Shukla SK. "Soil improvement and Pulses: Healthy Rural India". Global Journal of Bio-Science and Biotechnology 6 (2017): 04.

8. Dikshit A., et al. "Plant growth promotion by plant growth promoting rhizobacteria (PGPR) with nanomaterials in current agricultural scenario". Lap Lambert Academic Publishing (2013): 978-3-659-36774-8.

9. Adesemoye AO., et al. "Comparison of plant growth-promotion with Pseudomonas aeruginosa and Bacillus subtilis in three vegetables". Brazilian Journal of Microbiology 39 (2008)a: 423-426.

10. Adesemoye AO and Kloepper JW. "Plant-microbes interactions in enhanced fertilizer use efficiency". Applied Microbiology and Biotechnology 85 (2009): 1-12. 
11. Compant SW., et al. "Use of plant growth-promoting bacteria for bio-control of plant diseases: principles, mechanisms of action, and future prospects". Applied and Environmental Microbiology 71 (2005): 4951-4959.

12. Kloepper JW., et al. "Plant root-bacterial interactions in biological control of soil borne diseases and potential extension to systemic and foliar diseases". Australasian Plant Pathology 28 (1999): 21-26.

13. Sundara-Rao WVB and Sinha MK. "Phosphate dissolving micro-organisms in the soil and rhizosphere Indian". The Journal of Agricultural Science 33 (1963): 272-278.

14. Sindhu SS., et al. "Antagonistic effect of Pseudomonas spp. on pathogenic fungi and enhancement of plant growth in green gram (Vigna radiata)". Biology and Fertility of Soils 29 (1999): 62-68.

15. Clinical and Laboratory Standards Institute, Methods for Dilution Antimicrobial Susceptibility Tests for Bacteria That Grow Aerobically; Approved Standard-Seventh Edition. CLSI Document (2008): M7-A7.

16. Marsden SB. "Antioxidant Determinations by the Use of a Stable Free Radical”. Nature 181 (1958): 1199-1200.

17. Hilda R and Reynaldo F. "Phosphate solubilizing bacteria and their role in plant growth promotion". Biotechnology Advances 17 (1999): 319-339.

18. Priyanka P and Sindhu SS. "Potassium Solubilization by Rhizosphere Bacteria: Influence of Nutritional and Environmental Conditions". Journal of Microbiology Research 3.1 (2013): 2523.

19. Wu SC., et al. "Effects of biofertilizer containing N-fixer, P and $\mathrm{K}$ solubilizers and AM fungi on maize growth: a greenhouse trial". Geoderma 125 (2005): 155-166.

20. Moumita D., et al. "Plant growth promoting rhizobacteria enhance growth and yield of chilli (Capsicum annuum L.) under field conditions". Australian Journal of Crop Science 5.5 (2011): 531-536.

21. Vani T., et al. "Antioxidant properties of the ayurvedic formulation triphala and its constituents". Pharmaceutical Biology 35 (1997): 313-317.

\section{Assets from publication with us}

- Prompt Acknowledgement after receiving the article

- Thorough Double blinded peer review

- Rapid Publication

- Issue of Publication Certificate

- High visibility of your Published work

Website: www.actascientific.com/

Submit Article: www.actascientific.com/submission.php

Email us: editor@actascientific.com

Contact us: +919182824667 